\title{
Lymphoreticular Involvement in Human Immunodeficiency Virus Infection
}

\author{
Col MPS Sawhney*
}

\begin{abstract}
Background: Although lymphadenopathy, hepatomegaly and splenomegaly are commonly seen in human immunodeficiency virus (HIV) infection, little is known about the prognostic significance of these findings.

Method: A retrospective study of lymphoreticular involvement in 612 HIV-positive patients was done.

Result: Lymphadenopathy was found in $301(49.18 \%)$, hepatomegaly in $102(16.66 \%)$ and splenomegaly in $58(9.47 \%)$ patients. Sixty eight (32.54\%) of the 209 patients with only lymphadenopathy had acquired immunodeficiency syndrome (AIDS), as compared to $70(23.97 \%)$ of the 292 patients without lymphadenopathy or hepatosplenomegaly $\left(\chi^{2} 4.49, \mathrm{df}-1, \mathrm{p}<0.05\right)$. There was a higher chance of having AIDS if hepatomegaly was present with lymphadenopathy. Eight (72.73\%) of 11 patients with hepatomegaly alone, had AIDS. Thirty (68.18\%) of 44 cases with splenomegaly, with lymphadenopathy and hepatomegaly, three (50\%) of six cases having splenomegaly with lymphadenopathy and one $(33.33 \%)$ of three cases with splenomegaly had AIDS. Majority of lymphoreticular involvement cases were due to Mycobacterium tuberculosis infection. All 29 cases with abdominal lymphadenopathy and one with hilar lymphadenopathy had AIDS. Bilateral discrete cervical, axillary and inguinal lymphadenopathy was the most common presentation. CD4 counts were significantly $(\mathbf{p}<0.05)$ lower in those with lymphadenopathy and hepatosplenomegaly. Conclusion: HIV cases with lymphadenopathy and hepatomegaly should be investigated for the presence of opportunistic infection.
\end{abstract}

MJAFI 2008; 64 : 04-06

Key Words: Human Immunodeficiency Virus; Lymphadenopathy; Hepatomegaly; Splenomegaly

\section{Introduction}

L ymphadenopathy is commonly seen in early human immunodeficiency virus (HIV) infection. It is associated with improved outcome while regression is seen as a sign of disease progression [1]. Cervical, axillary, and inguinal lymph nodes are usually involved. Significant enlargement of thoracic or abdominal lymph nodes usually indicates an underlying opportunistic infection, such as pulmonary or disseminated tuberculosis, mycobacterium avium complex (MAC) disease, histoplasmosis or lymphoma [2]. Hepatomegaly and splenomegaly are common findings on abdominal computerised tomography [3]. However, prognostic significance of these findings in the Indian subcontinent is unclear. We studied the pattern of lymphoreticular involvement in HIV-positive patients in armed forces.

\section{Material and Methods}

This is a retrospective, hospital record based analytic study of newly diagnosed 612 cases of HIV infection. The medical records of these patients were analysed with a view to find out the pattern of lymphoreticular involvement. Haemogram, erythrocyte sedimentation rate, platelet count, urine analysis, liver function tests, veneral disease research laboratory test (VDRL), hepatitis B surface antigen (HBsAg), radiograph of the chest, ultrasound abdomen and tuberculin tests were carried out. CD4, CD8 and absolute lymphocyte counts (ALC) were done. Patients were classified into category A, B, C and diagnosed as having AIDS as per the revised guidelines [4].

Results

Out of 612 patients two were females. Of these 301 (49.18\%) had lymphadenopathy, $102(16.66 \%)$ hepatomegaly and 58 (9.47\%) splenomegaly. Two hundred and twelve (34.64\%) cases had acquired immunodeficiency syndrome (AIDS). Lymphoreticular involvement of these cases is shown in Table 1. There was significantly higher incidence of developing Table 1

Lymphoretiular involvement and incidence of AIDS in HIVpositive patients

$\begin{array}{lrrl}\text { Group } & \text { Number } & \text { Number with AIDS (\%) } \\ \text { Only L } & 209 & 68(32.54) \\ \text { L+H } & 42 & 32(76.19) \\ \text { L+H+S } & 44 & 30 & (68.18) \\ \text { L+S } & 6 & 3 & (50) \\ \text { Only H } & 11 & 8 & (72.73) \\ \text { H+S } & 0 & 0 & \\ \text { Only S } & 3 & 1 & (33.33) \\ \text { Without L, H or S } & 292 & 70 \quad(23.97) \\ \text { Total } & 612 & 212 & \end{array}$

Legend: L-lymphadenopathy; H-hepatomegaly; S-splenomegaly 
AIDS in those with only lymphadenopathy than in those without lymphadenopathy or hepatosplenomegaly $\left(\chi^{2} 4.49\right.$, $\mathrm{df}-1, \mathrm{p}<0.05)$. This increased by two and half times, if hepatomegaly was also present along with lymphadenopathy $\left(\chi^{2} 47.24, \mathrm{df}-1, \mathrm{p}<0.001\right)$. However presence of splenomegaly alone or in addition to lymphadenopathy and/or hepatomegaly did not further increase the incidence of AIDS..

Distribution of AIDS defining conditions in relation to lymphadenopathy and hepatosplenomegaly is shown in Table 2. Majority of lymphadenopathy, hepatomegaly and splenomegaly cases with AIDS were due to Mycobacterium tuberculosis infection. The diagnosis of tuberculosis was based on clinical assessment, chest radiograph, sputum examination and biopsy. Majority (96.23\%) had developed category $\mathrm{C}$ illness and in eight (3.77\%), AIDS was diagnosed with patients having CD4 counts less than 200/cmm without any associated category $\mathrm{C}$ condition. Three patients each with $(1.00 \%)$ and without $(0.96 \%)$ lymphadenopathy were

Table 2

AIDS cases with lymphadenopathy and hepatosplenomegaly

$\begin{array}{lccc}\begin{array}{l}\text { AIDS defining } \\ \text { condition }\end{array} & \begin{array}{c}\text { Lymphadenopathy } \\ (\%)\end{array} & \begin{array}{c}\text { Hepatomegaly } \\ (\%)\end{array} & \begin{array}{c}\text { Splenomegaly } \\ (\%)\end{array} \\ \text { Tuberculosis } & 122 *(91.72) & 71(95.95) & 36(94.74) \\ \text { PCP } & 2(1.50) & 2(2.70) & 0 \\ \text { Cryptococcosis } & 0 & 0 & 0 \\ \begin{array}{l}\text { Isosporiasis } \\ \begin{array}{l}\text { Oesophageal } \\ \text { candidiasis }\end{array}\end{array} & 1(0.75) & 0 & 0 \\ \begin{array}{l}\text { CD } 4 \text { count } \\ <200 / \text { cmm }\end{array} & 7(5.26) & 1(1.35) & 2(5.26) \\ \text { Total } & 133(100) & 74(100) & 38(100)\end{array}$

*Two in addition had $P$ carinii pneumonia (PCP) and one each had disseminated cryptococcosis and AIDS dementia having significant VDRL titre. Eight (7.87\%) and 17 (3.33\%) patients with and without hepatomegaly were HBsAg positive. One $(0.98 \%)$ patient each of hepatomegaly had latent syphilis, syphilitic meningitis and cirrhosis.

Average CD4, CD8, CD4:CD8 and ALC is shown in tables 3-5. It was observed that mean CD4 count was lower in those with lymphadenopathy as compared to those without it, although it was statistically not significant. The mean CD4 count was lower in patients with hepatomegaly and lymphadenopathy as compared to those without it, but it was statistically not significant, possibly due to small number of patients. The CD4 counts were significantly lower in patients with hepatosplenomegaly and lymphadenopathy than those without it. In addition, CD4 count of 106 was found in one case of hepatosplenomegaly without lymphadenopathy. CD4 count of 68 and CD 8 count of 140 was seen in one case of splenomegaly with lymphadenopathy.

Cervical lymphadenopathy was commonest, seen in 214 (34.96\%), followed by axillary in 211 (34.48\%), inguinal in 179 $(29.25 \%)$, retroperitoneal in $29(4.74 \%)$, epitrochlear in 16 $(2.61 \%)$, supraclavicular in nine $(1.47 \%)$, submandibular in three $(0.49 \%)$, hilar and posterior auricular in one $(0.16 \%)$ each (Table 6). Lymph nodes were matted in $13(2.12 \%)$.

All 29 cases of retroperitoneal lymphadenopathy had AIDS, 22 (75.86\%) had pulmonary tuberculosis, four (13.79\%)

Table 6

Distribution of lymphadenopathy in HIV-positive cases

$\begin{array}{lcccc}\text { Lymph nodes } & \begin{array}{c}\text { Bilateral } \\ (\%)\end{array} & \begin{array}{c}\text { Left only } \\ (\%)\end{array} & \begin{array}{c}\text { Right only } \\ (\%)\end{array} & \begin{array}{c}\text { Total } \\ (\%)\end{array} \\ \text { Cervical } & 190(88.78) & 11(5.14) & 13(6.07) & 214(100) \\ \text { Axillary } & 192(91.00) & 8(3.79) & 11(5.21) & 211(100) \\ \text { Inguinal } & 174(97.21) & 1(0.56) & 4(2.23) & 179(100)\end{array}$

Table 3

Lymphadenopathy and average CD4, CD8, CD4:CD8 and ALC CD4 (No. tested) CD8 (No. tested) CD4: CD8 (No. tested) ALC (No. tested)

$\begin{array}{lllll}\text { With lymphadenopathy only } & 219.05(20) & 872.37(18) & 0.251(18) \\ \text { Without lymphadenopathy and hepatosplenomegaly } & 292.14(34) & 931.54(24) & 0.314(24)\end{array}$

SD for CD4 counts- 144.07 and 238.22, SE-52.02, $\mathrm{p}>0.05, *$ No. $=$ number

Table 4

Hepatomegaly, lymphadenopathy and average CD4, CD8, CD4:CD8 and ALC

\begin{tabular}{|c|c|c|c|c|}
\hline & CD4 (No. tested) & CD8 (No. tested) & CD4: CD8 (No. tested) & ALC (No. tested) \\
\hline With hepatomegaly and lymphadenopathy & 252 & 692 & $0.212(11)$ & 1800 \\
\hline Without lymphadenopathy and hepatosplenomegaly & $292.14 \quad(34)$ & $931.54(24)$ & $0.314(24)$ & 2085.18 (17) \\
\hline
\end{tabular}

SD for CD4 counts-172.63 and 238.22, SE 87.34, p>0.05,* No.= number

Table 5

Hepatosplenomegaly, lymphadenopathy and average CD4, CD8, CD4:CD8 and ALC

\begin{tabular}{|c|c|c|c|c|}
\hline & CD4 (No. tested) & CD8 (No. tested) & CD4: CD8 (No. tested) & ALC (No. tested) \\
\hline With lymphadenopathy and hepatosplenomegaly & 184.60 & $1043.63(8)$ & $0.177(9)$ & 2320 \\
\hline Without lymphadenopathy and hepatosplenomegaly & $292.14(34)$ & $931.54(24)$ & $0.314(24)$ & 2085.18 (17) \\
\hline
\end{tabular}

SD for CD4 counts-102.60 and 238.22, SE 53.33, p<0.05, * No. $=$ number 
disseminated tuberculosis and one $(3.45 \%)$ each had tubercular lymphadenitis and tubercular pleural effusion. Two $(6.90 \%)$ patients had associated ascites. Of the 28 patients with epitrochlear, supraclavicular, submandibular and posterior auricular lymphadenopathy, five (31.25\%) out of 16 had bilateral involvement as compared to nine $(75 \%)$ out of 12 with unilateral involvement. The difference was statistically significant $\left(\chi^{2} 4.25, \mathrm{df}-1, \mathrm{p}<0.05\right)$.

\section{Discussion}

Bilateral discrete cervical, axillary and inguinal lymphadenopathy in HIV-positive patients was the commonest finding in this study, as reported by others also [2]. The HIV epidemic has been associated with a marked increase in pulmonary and extrapulmonary tuberculosis [5-8]. Involvement of retroperitoneal and hilar lymph nodes in our study was found to be a sign of opportunistic infection. All these patients had tubercular infection. In another study of lymphadenopathy in Blantyre, Malawi, $73 \%$ cases were having tuberculosis and $84 \%$ were later found to be HIV positive [9]. Asymmetrical involvement of lymph nodes (other than cervical, axillary and inguinal) and involvement of retroperitoneal and hilar lymph nodes is associated with significantly higher chance of developing AIDS. Debnath et al [10], reported a higher incidence of thoracic lymphadenopathy in HIV-positive patients as compared to HIV-negative controls.

Knollmann et al [3], in a study of 339 HIV infected patients found splenomegaly in $43.36 \%$, hepatomegaly in $42.48 \%$ and lymphadenopathy in $32.74 \%$ as compared to $9.47 \%, 16.66 \%$ and $4.74 \%$ respectively observed in our study. They also concluded that these findings lack prognostic relevance except in cases with large hepatomegaly, grossly enlarged lymph nodes or ascites, which indicate immunosuppression. In contrast, we found a positive correlation between hepatomegaly and development of AIDS. Presence of retroperitoneal lymphadenopathy was found to be a sign of opportunistic infection in our study. Aubry et al [11] concluded that combination of abdominal lymphadenopathy and/or serous exudates (peritoneal, pleural or pericardial) suggested disseminated tuberculosis in AIDS cases. Two cases in our study had abdominal lymphadenopathy with ascites and one had pleural effusion.

We found an increased association of AIDS in cases with lymphadenopathy possibly due to endemicity of tuberculosis in our country. Satyanarayana et al [12], in a study of fine needle aspiration cytology (FNAC) of lymph nodes in $196 \mathrm{HIV}$-positive patients demonstrated acid fast bacilli (AFB) with equal frequency in both symptomatic and asymptomatic groups. This suggests that many of the cases of generalised lymphadenopathy in HIV positive patients are tubercular in aetiology. We did not find any co-relation between splenomegaly and development of AIDS. Furrer [13], reported that splenomegaly was not associated with a higher risk of developing AIDS. To conclude, lymphadenopathy and hepatomegaly cases with HIV infection should be investigated for opportunistic infections.

\section{Conflicts of Interest}

None identified

\section{References}

1. Ioachim HL, Cronin W, Ray M, Maya M. Persistent lymphadenopathies in people at risk for HIV infection. Clinicopathological correlations and long-term follow-up in 79 cases. Am J Clin Pathol 1990; 93: 208-18.

2. Saag MS. Clinical spectrum of human immunodeficiency virus diseases. In: DeVita VT, Hellman S, Rosenberg SA, Curran J, Essex M. Fauci AS, editors. AIDS-Etiology, Diagnosis, Treatment and Prevention. $4^{\text {th }}$ ed. Philadelphia: LippincottRaven, 1997:203-14.

3. Knollmann FD, Maurer J, Grunewald T, Schedel H, Vogl TJ, Pohle HD, et al. Abdominal CT features and survival in acquired immunodeficiency. Acta Radiol 1997; 38: 970-7.

4. Centre for Disease Control. 1993 Revised classification system for HIV infection and expanded surveillance of definition for AIDS among adolescent and adults. MMWR 1992; 41:1-19.

5. Harries AD, Maher D, Mvula B, Nyangulu D. An audit of HIV testing and HIV serostatus in tuberculosis patients. Tubercle and Lung Disease 1995; 76: 413-7.

6. Raviglione MC, Narain JP, Kochi A. HIV-associated tuberculosis in developing countries: clinical features, diagnosis and treatment. Bulletin of the World Health Organisation 1992; 70: $515-26$

7. Raviglione MC, Snider DE, Kochi A. Global epidemiology of tuberculosis, morbidity and mortality of a worldwide epidemic. Journal of American Medical Association 1995; 273: 220-6.

8. Drobniewski FA, Pozniak AL, Uttley AHC. Tuberculosis and AIDS. J Med Microbiol 1995; 43: 85-91.

9. Bekedam HJ, Boeree M, Kamenya A, Liomba G, Ngwira B, Subramanyam VR, et al. Tubercular lymphadenitis:A diagnostic problem in the areas of high prevalence of HIV and tuberculosis. Transactions of The Royal Soc of Tropical Medicine and Hygiene 1997; 91: 294-7

10. Debnath J, Sreeram MN, Sangameswaran KV, Panda BN, Tiwari SC, Rakesh M, et al. Comparative study of chest radiographic features between HIV seropositive and HIV seronegative patients of pulmonary tuberculosis. MJAFI 2002; 58: 5-8.

11. Aubry P, Reynaud JP, Nbonyingingo C, Ndabaneze E, Mucikere E. Ultrasonographic data of the solid organs of the abdomen in stage IV human immunodeficiency virus infection. A prospective study of 101 cases in central Africa. Ann Gastroenterol Hepatol 1994; 30: 43-52.

12. Satyanarayana S, Kalghatgi AT, Muralidhar A, Prasad RS, Jawed KZ, Trehan A. Fine needle aspiration cytology of lymph nodes in HIV infected patients. MJAFI 2002; 58: 33-7.

13. Furrer H. Prevalence and clinical significance of splenomegaly in asymptomatic HIV- type I-infected adults. Swiss HIV cohort study. Clin Infect Dis 2000;30:943-5. 